\title{
Formação de Recursos Humanos de Nivel Médio em Saúde no Rio de Janeiro: A Experiência da Escola Técnica em Saúde Enfermeira lzabel dos Santos
}

\author{
Middle-Level Health Personnel Training in Rio de Janeiro: \\ The Izabel dos Santos Technical School Experience
}

\author{
Mário Roberto Dal Poz "; Regina Aurora T. Romano 2; \\ Milta B. Torres ${ }^{2} \&$ Mariliza V. Cortez ${ }^{2}$
}

DAL POZ, M. R.; ROMANO, R. A. T.; TORRES, M. B. \& CORTEZ, M. V. Middle-Level Personnel Training in Rio de Janeiro: The Izabel dos Santos Technical School Experience. Cad. Saúde Públ., Rio de Janeiro, 8 (1): 57-61, jan/mar, 1992.

As occurs throughout the country, there is a large number of non-qualified personnel employed in health services in Rio de Janeiro, jeopardizing the quality of health care. In order to change this situation, the authors suggest the technical qualification, at elementary and high school levels, in health skills approved by the Federal Council of Education and discuss the experience of the Izabel dos Santos Technical school, of the State Secretariat of Health. Created as an "Open School", its pedagogical process is based on the "problematization" of reality. The Izabel dos Santos School includes 8 units wich are already operating with 225 students/health workers.

Keywords: Health Personnel; Teaching for Health; Learning

\section{INTRODUÇÃO}

Ao longo desses últimos anos, o sucateamento dos serviços públicos de saúde não se limitou às instalações físicas, equipamentos e à defasagem tecnológica. Também os trabalhadores do setor saúde passaram por um processo de deterioração, pela ausência de investimento na sua formação e atualização, ao lado da inexistência de planos de carreiras, cargos e salários.

A pesquisa Assistência Médica Sanitária, realizada pelo IBGE em estabelecimentos de saúde (Brasil, 1987), nos dados da Força de Trabalho em Saúde, demonstrou que, no Brasil, $33,4 \%$ dos trabalhadores típicos da saúde exercem ocupações de nivel elementar, sem nenhuma formação especifica que os habilite a

\footnotetext{
'Instituto de Medicina Social da Universidade do Estado do Rio de Janeiro. Rua São Francisco Xavier, $524-7^{8}$ andar, bloco D, Rio de Janeiro, RJ, 20550, Brasil.

2 Escola de Formação Técnica em Saúde, SES/RJ. Rua da Passagem, 179, Rio de Janeiro, RJ, 22290, Brasil.
}

prestar uma assistência à saúde com qualidade. A mesma pesquisa mostrou que $19,12 \%$ dos trabalhadores, no Estado do Rio de Janeiro, não possuem tal habilitação profissional, excluídos deste percentual os trabalhadores de apoio administrativo.

Pesquisa realizada nas categorias da enfermagem (Conselho Federal de Enfermagem, 1985) demonstrou que os atendentes representam $63,8 \%$ do total da equipe de enfermagem no Brasil. No Estado do Rio de Janeiro, este segmento representa $32,8 \%$.

Diante deste quadro, impōe-se que o setor saúde adote estratégias próprias para, a médio e longo prazos, capacitar essa força de trabalho para o exercício de suas funções.

\section{O PAPEL DO SETOR SAÚDE NA FORMAÇÃO DE RECURSOS HUMANOS}

A Constituição federal (Brasil, 1989) e a fluminense (Rio de Janeiro, 1989) estabelece- 
ram como competência do Sistema Único de Saúde ordenar a formação de recursos humanos na área da saúde. Ocorre que a formação de recursos humanos é uma atividade cuja responsabilidade não é originalmente do setor saúde. Porém, diante da necessidade de qualificar esse significativo contingente sem preparação formal, já existente nos serviços de saúde, e também da incapacidade do setor educacional de prover, qualitativa e quantitativamente, os recursos humanos de nível médio necessários à operacionalização do setor saúde, os órgãos de recursos humanos vêm buscando formas de intervir nesta situação.

Para vencer este desafio, e com o apoio de técnicos do Grupo Assessor de Recursos Humanos da Organização Pan-americana de Saúde, foi recentemente implantada no Estado do Rio de Janeiro a Escola de Formação Técnica em Saúde Enfermeira Izabel dos Santos (ETFS), com o objetivo de promover o leque de habilitações de $1^{2}$ e $2^{2}$ graus daquelas atividades assistenciais, de apoio diagnóstico e administrativo aos serviços de saúde.

Trata-se de uma escola voltada para a qualificação profissional dos trabalhadores dos serviços públicos de saúde do Estado do Rio de Janeiro, cidadãos social e historicamente determinados.

\section{HISTÓRICO, ESTRUTURA E RECURSOS}

A Escola de Formação Técnica em Saúde tem por desafio qualificar doze mil trabalhadores sem habilitação profissional que atuam no setor público de saúde no Estado do Rio de Janeiro, dos quais nove mil são atendentes de enfermagem (Instituto Brasileiro de Geografia e Estatística, 1987). A sua concepção pedagógica teve origem no "Projeto de Formação de Pessoal de Nivel Médio em Larga Escala", desenvolvido em decorrência do Acordo Interministerial MS/Mec/MT/MPAS/Opas (Ministério da Saúde, 1985).

O primeiro espaço de aplicação desse projeto foi a "Escola de Auxiliares de Enfermagem do HSE/Inamps", a partir de 1986, reorientando o processo de formação ali existente desde 1954. A primeira turma, composta exclusivamente por servidores do Inamps, teve inicio já em 1987.

A assinatura do Convênio Suds 01/88 abriu a perspectiva e mostrou a necessidade de ampliar a Formação para os servidores das demais instituições integrantes do sistema de saúde. Assim, a experiência foi sendo ampliada e aprimorada nos limites permitidos pelo Parecer $n^{2} 477 / 87$ do Conselho Estadual de Educação/RJ, que autorizou o funcionamento da "Escola de Auxiliares de Enfermagem do HSE/Inamps" em seus núcleos de ensino.

O novo sistema de saúde previsto na C.F. (Brasil, 1989), ao intensificar o processo de municipalização no Estado do Rio de Janeiro tornou crítica a limitação geográfica (capital) e do leque de habilitações (auxiliares de enfermagem) da Escola do HSE. Impunha-se, então, como necessidade a organização de uma nova escola que, atendendo aos princípios de descentralização, atendimento integral e qualidade da assistência, não rompesse com a concepção pedagógica do Projeto Larga Escala.

A partir destes princípios, foi criada, pelo Decreto Estadual $\mathrm{n}^{2} 13.802$, de $1 / 11 / 89$, a Escola de Formação Técnica em Saúde (Rio de Janeiro, 1989), que teve seu regimento e projetos de cursos autorizados pelo Parecer $n^{2} 150 / 90$ do Conselho Estadual de Educação (Rio de Janeiro, 1990). Dessa forma, a Escola está apta a ministrar os cursos de Auxiliar de Enfermagem, Atendente de Consultório Dentário, Técnico de Higiene Dental, Técnico de Radiologia, Técnico de Administração e Técnico de Citopatologia nas unidades assistenciais em todo o Estado, com a possibilidade de inclusão de novos cursos.

Estruturada na Secretaria de Estado de Saúde e subordinada à Coordenadoria de Desenvolvimento de Recursos Humanos (Rio de Janeiro, 1989), recebe recursos do Fundo Estadual de Saúde (Rio de Janeiro, 1990), através de desembolso descentralizado, o que the garante as condições de funcionamento.

\section{CONCEPÇÃO PEDAGÓGICA E METODOLOGIA}

A Escola tem por finalidade ministrar cursos 
de qualificação profissional, pela via supletiva de ensino, à clientela já engajada na força de trabalho ou em processo de admissão nos serviços de saúde.

A opção pedagógica adotada é a da problematização, que, segundo Bordenave:

... parte da base que, em um mundo de mudanças rápidas, $o$ importante não são os conhecimentos ou idéias nem os comportamentos corretos e fáceis que se espera, mas sim o aumento da capacidade do aluno - Participante e Agente da

Transformação Social - para detectar os problemas reais, buscar para eles soluçōes originais e criativas (Luchesi, G. et al., 1989).

Trata-se de utilizar como princípio pedagógico o trabalho, não no sentido mecanicista, mas como reflexão sobre a prática, pois é através da vivência que cada aluno traz das unidades assistenciais que se dá a construção do conhecimento. Parte-se de um processo que possibilite observar a realidade (problema), separar o que é relevante, teorizar acerca desse problema, confrontar a realidade com sua teorização para formular hipóteses de solução e, por último, aplicar à realidade (prática), segundo a concepção do arco de Charles Maquerez (Luchesi, G. et al., 1989).

A metodologia utilizada para esta proposta, por sua adequação, é a de integração ensino serviço, visando também alcançar a meta de qualificação da assistência de saúde.

Neste processo, os alunos são o sujeito e os instrutores - supervisores, profissionais de nivel superior do próprio serviço, são os facilitadores. O processo de ensino-aprendizagem é conduzido de forma flexivel, tanto no plano curricular como no plano de execução, buscando-se respeitar o ritmo de cada aluno. A construção do conhecimento ocorre de forma reflexiva, visando preparar cidadãos que tenham a capacidade de modificar a realidade (Santos, I. dos et al., 1988).

Este processo permite aos alunos adquirir consciência dos fundamentos científicos e sociais de cada ação de saúde, concomitante ao exercício das habilidades psicomotoras correspondentes e ao compromisso com a nova ética profissional.
Os currículos aplicados nos cursos ainda são por disciplinas, porém já há muitos trabalhados no sentido de integrar ensino e prática profissional, facilitar a interligação dos conhecimentos aprendidos em cada disciplina e promover a integração professor - aluno na investigação e na busca de esclarecimentos e propostas, de modo que o aluno tenha condiçōes de buscar, ativamente, seu próprio conhecimento. Esta forma de trabalhar o currículo é uma estratégia adotada para, quando se concluir a elaboração dos currículos integrados (ainda em fase de elaboração pelo Grupo de Assessoria de Recursos Humanos da OPS/Brasil), a EFTS esteja em condições de aplicá-los.

O mecanismo de avaliação é processual $e$ se inicia com o acompanhamento sistemático da evolução do educando na construção do seu conhecimento, sendo considerado como parte integrante do planejamento curricular, estando presente em todos os estágios de seu desenvolvimento e não apenas confinado aos seus resultados finais (Luchesi, G. et al., 1989).

\section{EXECUÇÃO DESCENTRALIZADA}

Para alcançar o Sistema de Saúde de todo o Estado do Rio de Janeiro, a execução dos cursos é descentralizada, através dos Centros de Execução Programática Descentralizada (CEPD), instalados nos serviços de saúde dos municípios (Escola Aberta). As diversas habilitações são implantadas gradativamente, a partir do diagnóstico de necessidade e da existência de condições técnicas e pedagógicas, respeitando-se as peculiaridades locais.

O apoio técnico-pedagógico ao grupo local é feito pela própria direção geral com os coordenadores de cada área de habilitação. Este grupo técnico central se desloca aos diversos municipios, em processo de supervisão permanente, para desenvolver estratégias de capacitação técnica e pedagógica ao corpo docente.

O serviço de saúde local, além de sediar o curso, também é utilizado como campo de aprendizagem, diminuindo o tempo de afastamento do servidor do serviço.

Para viabilizar a implantação de um CEPD municipal, fazem-se necessárias a vontade 
política do Secretário Municipal de Saúde e a existência de serviços de saúde compativeis com a natureza de cada habilitação profissional, de profissionais de nível superior relativos a cada habilitação pretendida e, ainda, de trabalhadores de saúde sem qualificação prévia, com o primeiro grau completo ou em vias de completar.

Nos municípios onde a clientela não tem $o$ grau de escolaridade exigido pelo sistema formal de ensino, faz-se necessário o trabalho conjunto com a Secretaria Municipal de Educação para viabilizar a formação geral do grupo por via supletiva ou ainda outras formas legais adotadas pela educação.

A participação dos municípios é formalizada por Termo Aditivo ao Convênio de Municipalização, onde se estabelecem claramente as responsabilidades da Secretaria de Estado de Saúde e das Prefeituras Municipais.

Assim, o processo de formação de pessoal de nível médio, promovido pela Escola, apóia e impulsiona a descentralização e a municipalização do sistema de saúde.

\section{RESULTADOS}

Durante o ano de 1990, foram implantados CEPD nos municípios de Angra dos Reis, São Fidélis (consorciado com Santo Antônio de Pádua, Bom Jesus de Itabapoana e Miracema) e Três Rios (consorciado com Sapucaia e Paraíba do Sul). Outros municípios, em todo o Estado, já estão promovendo o levantamento das características da força de trabalho em saúde e dos recursos físicos, materiais e humanos para a implantação de outros núcleos locais em Macaé, Cachoeiras de Macacu, Natividade e Santo Antônio de Pádua.

Atualmente estão em curso 8 (oito) turmas de Auxiliar de Enfermagem, sendo 5 (cinco) na capital e 3 (três) no interior, num total de 225 (duzentos e vinte cinco) alunos-servidores.

Também já iniciaram sua formação turmas de Técnico de Higiene Dental, Técnico de Administração e Técnico de Citopatologia, num total de sessenta alunos-servidores.

O potencial atual de formação é de seiscentos alunos por ano, considerando-se as caracteristicas de Escola Aberta, com planejamento para implantação nas 8 (oito) regiões do estado.

Uma vez implantados todos os cursos autorizados pelo CEE e cobertas as oito regiões do estado, será possível expandir o número de CEPD, bem como solicitar autorização para novas habilitações, atendendo às necessidades de formação de pessoal de saúde diagnosticadas nos municípios, ampliando, assim, as potencialidades da ETFS.

\section{CONCLUSÃO}

Durante o processo percorrido desde a elaboração do projeto de formação de pessoal de nivel médio para o Estado do Rio de Janeiro até a atual etapa de descentralização e expansão dos cursos, dificuldades foram ultrapassadas e outras ainda estão por superar. Apesar do discurso oficial apontar a questão dos recursos humanos como fundamental para a reformulação do velho e a implantação do novo sistema de saúde, basta um olhar superficial sobre a realidade para constatar o oposto. Os baixos salários, a inexistência de planos de carreira, a contratação sem parâmetros de lotação, a bipolaridade da força de trabalho em saúde são, dentre outros, sinais da baixa prioridade que os governos têm dado ao setor de RH.

Essa política de recursos humanos foi e continua sendo um forte entrave a projetos de qualificação de pessoal do setor saúde.

A implantação da Escola de Formação Técnica em Saúde Enfermeira Izabel dos Santos, com base no Projeto de Formação de Pessoal de Nivel Médio em Larga Escala, objeto do Acordo entre os Ministérios da Saúde, Educação e Previdência Social e a Opas/OMS, é uma experiência em curso na qual sobressaem vários aspectos positivos, como a metodologia problematizadora, o regimento inovador e a descentralização. Ressalte-se, ainda, os baixos custos operacionais, pois, na metodologia adotada, os instrutores-supervisores e os administrativos são os profissionais que já trabalham nos serviços de saúde. 


\section{RESUMO}

DAL POZ, M. R.; ROMANO, R. A. T.; TORRES, M. B. \& CORTEZ, M. V.

Formação de Recursos Humanos em Saúde no Rio de Janeiro: A experiência da Escola Técnica Enfermeira Izabel dos Santos. Cad. Saúde Públ., Rio de Janeiro, 8 (1): 57-61, jan/abr, 1992.

No Estado do Rio de Janeiro, assim como no resto do pais, os serviços de saúde empregam grande quantidade de servidores não habilitados, dificultando uma assistência à saúde de qualidade. Para reverter essa situação, os autores propõem a formação técnica, a nivel de $1^{2}$ e $2^{2}$ graus, dos servidores nas habilitações de saúde aprovadas pelo Conselho Federal de Educação e analisam a experiência da Escola Técnica Enfermeira lzabel dos Santos, da Secretaria de Estado de Saúde do Rio de Janeiro. O processo pedagógico tem por base a problematização da realidade. Concebida como escola aberta, já implantou 8 núcleos descentralizados, com um total de 225 alunos-servidores.

Palavras Chave: Recursos Humanos em Saúde; Ensino-Aprendizagem em Saúde

\section{REFERÊNCIAS BIBLIOGRÁFICAS}

BRASIL, 1989. Constituição da República Federativa do Brasil: de 5 de outubro de 1988. São Paulo: Atlas.

BRASIL. MINISTÉRIO DA SAÚDE, 1987. Projeto de Formação de Pessoal de Nivel Médio em Larga Escala: Acordo Mec/MPAS/MS/Opas. Brasilia: SMARH/Ministério da Saúde.

CONSELHO FEDERAL DE ENFERMAGEM, 1985. $O$ Exercicio da enfermagem nas Instituiçōes de Sauide no Brasil: 1982/1983. Vol. 1, Rio de Janeiro: CFE.

INSTITUTO BRASILEIRO DE GEOGRAFIA E ESTATISTICA, 1987. Estatistica de Saude: Assistência Médico-Sanitária. Vol. 12, Rio de Janeiro: Fundaçāo IBGE.

LUCHESI, G; HOLANDA, H. \& SANTOS, I., 1989. Capacitação Pedagógica para instrutor/supervisor: área da saúde. Brasilia: SMARH/Ministério da Saúde.
RIO DE JANEIRO (estado), 1989. Assembléia Legislativa. Constituição do Estado do Rio de Janeiro. Diário Oficial do Estado do Rio de Janeiro, 5 outubro.

RIO DE JANEIRO (estado), 1989. Poder Executivo. Decreto N2 13.802. Cria a Escola de Formação Técnica em Saúde e dá outras providências. Diário Oficial do Estado do Rio de Janeiro, 29 novembro.

RIO DE JANEIRO (estado), 1989. Secretaria de Estado de Saúde. Resolução $\mathrm{n}^{8}$ 542. Diário Oficial do Estado do Rio de Janeiro, 27 novembro.

RIO DE JANEIRO (estado), 1990. Conselho Estadual de Educação. Parecer № 150. Aprova Regimento Escolar e autoriza cursos da Escola Técnica em Saúde. Diário Oficial do Estado do Rio de Janeiro, 25 julho.

RIO DE JANEIRO (estado), 1990. Secretaria de Estado de Saúde. Resolução No 567. Diário Oficial do Estado do Rio de Janeiro, 20 abril.

SANTOS, I. dos; SOUZA, A. M. A. \& GALVAO, E. A., 1988. Subsídios para a formulação de uma política de profissionalizaçâo para o pessoal de enfermagem, sem qualificação especifica, empregado no setor saúde - Brasil. Educación Médica y Salud, 22: 191-199. 